\title{
A 4q35.2 subtelomeric deletion identified in a screen of patients with co-morbid psychiatric illness and mental retardation Ben S Pickard*1, Edward J Hollox ${ }^{3}$, M Pat Malloy1,2, David J Porteous, Douglas HR Blackwood ${ }^{2}$, John AL Armour ${ }^{3}$ and Walter J Muir ${ }^{2}$
}

\author{
Address: ${ }^{1}$ Medical Genetics, Molecular Medicine Centre, Univ. of Edinburgh, Western General Hospital, Crewe Road, Edinburgh, EH4 2XU, UK, \\ 2Psychiatry, Univ. of Edinburgh, Royal Edinburgh Hospital, Morningside Park, Edinburgh, EH10 5HF, UK and ${ }^{3}$ Institute of Genetics, Univ. of \\ Nottingham, Queen's Medical Centre, Nottingham, NG7 2UH, UK \\ Email: Ben S Pickard* - ben.pickard@ed.ac.uk; Edward J Hollox - Ed.Hollox@nottingham.ac.uk; M Pat Malloy - Pat.Malloy@ed.ac.uk; \\ David J Porteous - David.Porteous@ed.ac.uk; Douglas HR Blackwood - dblack@srv1.med.ed.ac.uk; \\ John AL Armour - John.Armour@nottingham.ac.uk; Walter J Muir - wjmuir@srv1.med.ed.ac.uk \\ * Corresponding author
}

Published: 13 August 2004

BMC Medical Genetics 2004, 5:21 doi:10.1 186/147/-2350-5-21
Received: 16 April 2004

Accepted: 13 August 2004

This article is available from: http://www.biomedcentral.com/147I-2350/5/2I

(c) 2004 Pickard et al; licensee BioMed Central Ltd.

This is an open-access article distributed under the terms of the Creative Commons Attribution License (http://creativecommons.org/licenses/by/2.0), which permits unrestricted use, distribution, and reproduction in any medium, provided the original work is properly cited.

\begin{abstract}
Background: Cryptic structural abnormalities within the subtelomeric regions of chromosomes have been the focus of much recent research because of their discovery in a percentage of people with mental retardation (UK terminology: learning disability). These studies focused on subjects (largely children) with various severities of intellectual impairment with or without additional physical clinical features such as dysmorphisms. However it is well established that prevalence of schizophrenia is around three times greater in those with mild mental retardation. The rates of bipolar disorder and major depressive disorder have also been reported as increased in people with mental retardation. We describe here a screen for telomeric abnormalities in a cohort of 69 patients in which mental retardation co-exists with severe psychiatric illness.
\end{abstract}

Methods: We have applied two techniques, subtelomeric fluorescence in situ hybridisation (FISH) and multiplex amplifiable probe hybridisation (MAPH) to detect abnormalities in the patient group.

Results: A subtelomeric deletion was discovered involving loss of $4 q$ in a patient with co-morbid schizoaffective disorder and mental retardation.

Conclusion: The precise region of loss has been defined allowing us to identify genes that may contribute to the clinical phenotype through hemizygosity. Interestingly, the region of $4 q$ loss exactly matches that linked to bipolar affective disorder in a large multiply affected Australian kindred.

\section{Background}

The isolation of unique DNA probes from the sub-telomeric regions of all chromosomes has opened up a field of cytogenetics research that was previously inaccessible to conventional karyotyping protocols [1]. Since then a number of studies have shown that cryptic structural abnormalities (deletions, duplications etc.) in the subtelomeric regions are relatively commonly found in groups of individuals with idiopathic mental retardation (UK; learning disability; LD). The biological attributes of these 
chromosomal regions may explain this interesting link. The frequency of meiotic recombination is at its highest at the ends of chromosomes (recently confirmed in the Icelandic microsatellite map of the human genome [2]). Therefore errors in this process should randomly result in a greater frequency of unbalanced chromosome rearrangement products at telomeres. There also appears to be a greater density of genes at the ends of some chromosomes, especially those with non-staining R-bands. Thus, any telomeric copy number change is likely to affect several genes; potentially resulting in clinical features typical of a contiguous gene syndrome - dysmorphisms, developmental delay and mental retardation. A number of reports have now shown that $0.5 \%-23 \%$ of idiopathic mental retardation cases are associated with cryptic translocations in the vicinity of chromosome telomere (see [317] and [18] for a recent review).

FISH, using a commercially available set of subtelomeric probes is the most commonly used screening technique $[19,20]$. Variations on the theme of FISH (e.g. SKY and CGH) have also been employed. More recently, methods that rely on the detection of copy number changes at subtelomeric loci have been described. MAPH [21-24] is one such technique in which probes are representatively amplified by the polymerase chain reaction following hybridisation to a patient's genomic DNA sample to generate a quantitative profile of subtelomeric sequence copy number.

Psychiatric disorders such as schizophrenia (SCZ) and bipolar affective disorder (BPAD) are relatively common in the general population and there is much evidence for a genetic component to susceptibility (for a review see [25]). However, it is clear from the lack of consistent findings from linkage mapping and association studies that they are likely to be complex and aetiologically heterogeneous disorders. For example, several genes might act simultaneously (oligogenic action) or interact (epistasis) to produce the clinical phenotype in any individual, and those genes might be different in different individuals (locus heterogeneity). An alternative to cohort based linkage and association approaches uses cytogenetic abnormalities as direct pointers to candidate gene loci and this has been successfully applied to patients with psychiatric disorders resulting in the identification of a number of candidate susceptibility genes including DISC1/DISC2 [26], DIBD1 [27] and GRIA3 [28]. The chromosome abnormalities that disrupted these genes were reciprocal translocations visible by standard cytogenetic methods.

The risk of schizophrenia and affective disorders in patients with idiopathic mild mental retardation is significantly raised and it is well established that schizophrenia is three times more common in this group than the gen- eral population and that there is a strong familial element [29]. Both bipolar illness and major depressive disorder have also been described as of increased prevalence in the population with mild mental retardation. The study also revealed a previously undetected complex re-arrangement between chromosomes 2 and 11, and a case of trisomy X, but did not address subtelomeric changes. It strongly suggested however that the co-association between mental retardation and schizophrenia is highly familial with greater rates of both schizophrenia and co-morbid schizophrenia/mental retardation occurring in the families of co-morbid probands compared to families of probands with schizophrenia alone or with mental retardation alone. Limbic system (amygdalo-hippocampal) neuropathology is especially pronounced in this group [30]. We have formed the hypothesis that patients who are co-morbid for severe psychiatric illness and mental retardation may be homogenous in their pathophysiology and that, in addition to large-scale structural chromosomal abnormalities, they may harbour as yet undetected cryptic telomeric changes. To test this we have screened a series of 69 patients co-morbid for mental retardation and psychiatric illness using fluorescence in situ hybridisation (FISH) and multiplex amplifiable probe hybridisation (MAPH).

\section{Methods \\ Patient Cohort}

Local research ethics permission was obtained for this study. The patients were initially ascertained through computerised psychiatric clinical case-registers that allowed us to identify adults with dual diagnosis of psychosis and mental retardation. A specific psychiatry service exists in Scotland to meet the needs of patients with mental retardation who also suffer from psychiatric disorders and initial clinical diagnoses were confirmed by consultation between the relevant specialist clinician involved and the research team member who is also a specialist in the psychiatry of mental retardation (WM). Confirmation that IQ fell within the mild range of mental retardation was obtained from case records.

69 patients with mild mental retardation (IQ 70 to around 50) and a referral diagnosis of co-existing schizophrenia or major affective disorder were studied. Parental samples were not available in many cases due to the age of the probands. This cohort is a subset of 74 originally ascertained subjects: 5 were removed because of aneuploidy ( 2 cases of $47(\mathrm{XXX})$ ) or after more thorough psychiatric evaluation. One discounted subject with only mental retardation possessed a $6 \mathrm{q}$ subtelomeric deletion as determined by several MAPH probes (data not shown). The lifetime version of the Schedule for Affective Disorders and Schizophrenia (SADS-L [31]) along with extensive case record review, and interviews with key carers and relatives was used to gather the information needed to 
Table I: Subject classification and analysis Breakdown of subjects into their diagnostic categories and applied experimental methodology. MR; mental retardation, SCZ; schizophrenia, BPI; bipolar affective disorder I, SCAFF; schizoaffective disorder, UFP; unspecified functional psychosis, UPR; unipolar depression.

\begin{tabular}{lccc}
\hline Clinical category & MAPH alone & MAPH and FISH & FISH alone \\
\hline MR/SCZ & 34 & 7 & 8 \\
MR/BPI & 6 & 3 & 2 \\
MR/SCAFF & 1 & 2 & 0 \\
MR/UFP & 3 & 0 & 2 \\
MR/UPR & 1 & 0 & 0 \\
TOTAL SCREEN & 45 & 12 & 12 \\
\hline
\end{tabular}

make a diagnosis of schizophrenia or affective disorder according to the Diagnostic and Statistical Manual $4^{\text {th }}$ Edition (DSM-IV [32]). Diagnosis was finalised by consensus between two experienced psychiatrists (DB, WM) one of whom specialises in the psychiatry of mental retardation (WM). SADS-L has previously been successfully used in people with mild mental retardation [29] to establish psychiatric diagnoses.

Overall 49 subjects met the DSM-IV criteria for definite schizophrenia, 3 for schizoaffective disorder, 11 for Bipolar I Disorder, 1 for recurrent Major Depressive Disorder (unipolar depression). In addition, 5 subjects were diagnosed as having a unspecified functional psychosis (DSMIV 298.9, Psychotic disorder NOS).

None had co-existing Down Syndrome or Fragile X disorder. A breakdown of the patients into their clinical categories and methodology of screening is presented in table 1 .

\section{DNA extraction}

DNA was extracted from venous blood samples (10 mls) of all patients by standard methods using Nucleon BACC2 kits (Nucleon Biosciences). $1 \mathrm{mg} / \mathrm{ml}$ dilutions were prepared for MAPH.

\section{MAPH}

All 57 MAPH samples were tested in triplicate using the subtelomeric screening set described previously [23]. All samples were anonymised prior to MAPH analysis. Each sample was tested three times, and putative positives identified by a univariate method (standard hypothesis testing against a normal distribution) and multivariate methods employed by the software SYSTAT 8.0 (Bivariate scattergraphs and Hadi outlier analysis). Four putative positives were divided into one confident (univariate analysis, $\mathrm{p}<$ 0.01 , corrected for multiple observations) and three possible (univariate analysis, $\mathrm{p}<0.05$, corrected for multiple observations, Hadi outlier distance $>4$, all three results reporting a consistent change: either all $>1.0$ or $<1.0$ ) positive results. The three "possible" positives have since been discounted since they involved gain of the 20p telomeric probe ST18E1, which from experience with normal control subjects has shown to have unacceptably high measurement error. This probe has been replaced in more recent formulations of the subtelomeric probe set.

\section{Subtelomeric FISH}

Blood samples from a subset of the patients were cultured in Peripheral Blood Medium (Sigma) for 72 hours. After colcemid treatment for one hour, lymphocytes were lysed and fixed in methanol:acetic acid (3:1). Fixed metaphase material was dropped onto microscope slides. Each slide was hybridised by three fluorescently labelled probe mixes (ToTelVysion, Vysis Inc.) under separate coverslips. All 15 mixes covering every subtelomeric region for a patient could thus be analysed on 5 slides. Images were captured on a Zeiss Axioskop2 microscope coupled to a Macintosh G4 computer running SmartCapture2.1 software (Digital Scientific). Five metaphases were scored for each probe mix.

\section{Results}

\section{A subtelomeric deletion identified in one subject}

Complete accord was seen in the 12 instances where both screening methodologies were used. The FISH approach did not detect any subtelomeric abnormalities (including balanced translocations, which would not be observable by MAPH). However, MAPH identified a subject with a loss of one copy of the $4 \mathrm{q}$ subtelomeric region $\left(\mathrm{p}<1 \times 10^{-}\right.$ 3 , corrected for multiple observations). It is unlikely that this copy number change $\left(4 \mathrm{q}^{-}\right)$defined by MAPH represents an irrelevant polymorphism; no similar change was found on analysis of 83 unrelated control individuals, giving an upper ( $95 \%$ confidence) limit of $1.6 \%$ for the frequency of this variant.

\section{Precise definition of $4 q$ loss}

Additional MAPH probes were designed to determine the extent of the $4 \mathrm{q}$ deletion (fig. 1). The results show that the proximal boundary of the subtelomeric deletion is between the FAT gene and the proximal end of clone 


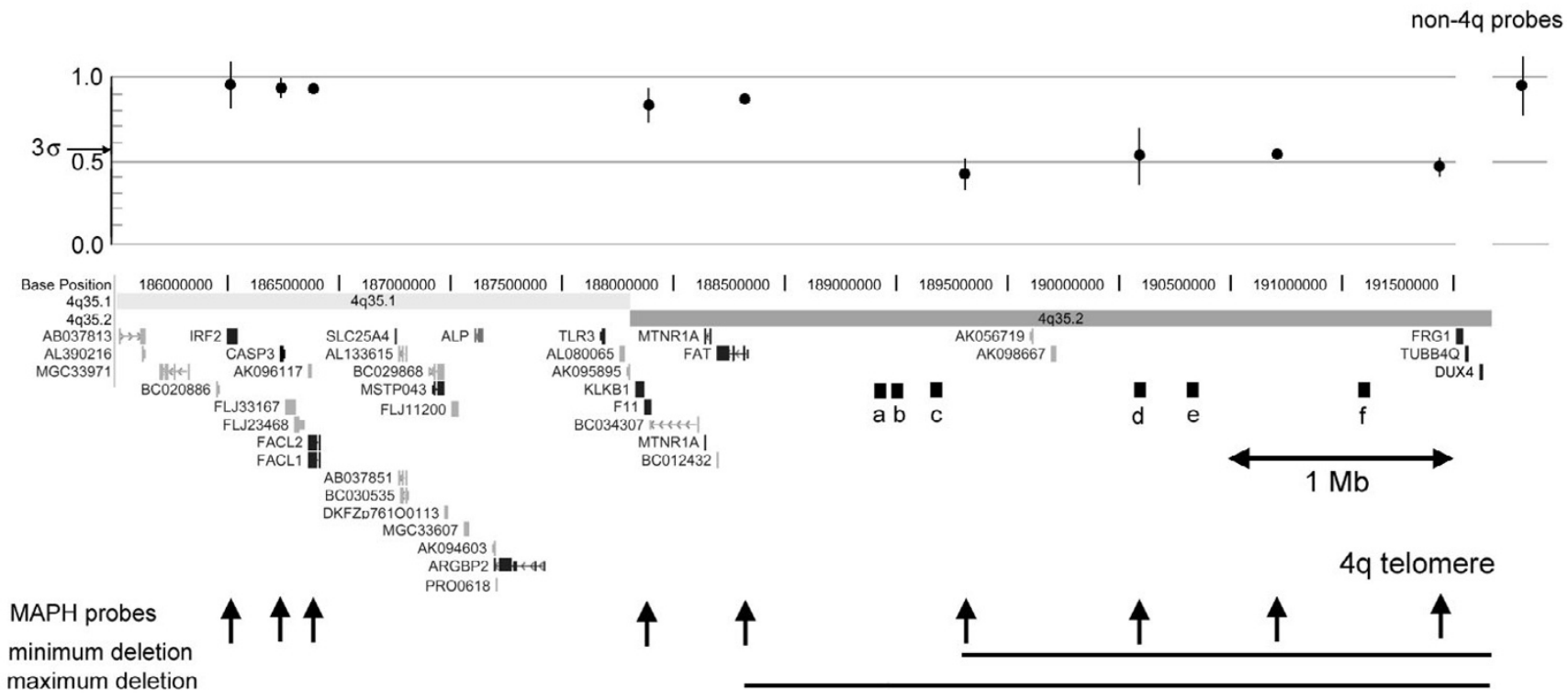

\section{Figure I}

Subtelomeric region of chromosome 4q Only annotated, unique chromosome sequence is shown, derived from the November 2002 version of the UCSC Human Genome assembly (subtelomeric repeats would extend to the right of the diagram). A scale bar and the gene content (see Table 2) of the region are shown. The positions of the MAPH markers are also shown which allowed the maximum and minimum extents of the deletion to be defined (black bar). Above the chromosome region is shown the result of duplicate analysis from each MAPH probe (mean $+/-95 \% \mathrm{Cl}$ ), together with the 3 standard deviation threshold and the results from the other control probes (mean $+/-95 \% \mathrm{Cl}$ ).

Table 2: Gene content of 4q deletion Genes/putative transcriptional units within the deleted region on chromosomes 4q. ESTs a-f are represented in figure I. An attempt to gauge the approximate expression levels of each gene was based on the number of EST clones present in the UCSC Human Genome Browser (Nov.2002/Apr.2003 releases). A brief summary of gene function and a representative accession number, where informative, is also included. TUBB4Q (4q35) is omitted from this list because it is a confirmed pseudogene.

\begin{tabular}{|c|c|c|}
\hline 4q35 GENE & EST exp. & Function/comments \\
\hline FAT & ++++ & Cadherin-related tumor suppressor homologue precursor \\
\hline EST a & + & (BE856720) Novel. \\
\hline EST $b$ & + & (BM806339) Novel. Contains 5 I/2 copies of 34 aa repeat motif \\
\hline EST c & ++ & (Al917275) Novel. No obvious ORF \\
\hline ZFP42/FLJ32/57 & + & (AK056719) Similar to transcriptional repressor protein YYI \\
\hline FLJ2580I & + & $\begin{array}{l}\text { (AK098667) Protein contains SMC (chromosome segregation ATPase) domain and PRY/SPRY domains } \\
\text { (unknown function). }\end{array}$ \\
\hline EST d & +++ & (BU57I I87) Novel. \\
\hline EST e & + & (BC033535) Novel. \\
\hline EST $f$ & + & (BC029568) LOC256307 novel predicted gene \\
\hline FRGI & ++++ & Facioscapulohumeral muscular dystrophy region gene I \\
\hline DUX4 & + & Homeobox protein, multiple copies. \\
\hline
\end{tabular}

713 c19 (Genbank accession number AC108073). P values for boundary probes $($ Ho, value $=1.00), \mathrm{p}<5 \times 10^{-5}$ for deletion and $\mathrm{p}>0.05$ for normal dosage. This $4 \mathrm{q}$ dele- tion encompasses a region of annotated genomic DNA of approximately $3 \mathrm{Mb}$. The transcript map of this region is not yet completely defined (see Table 2) but contains at 
least 10 transcriptional units with varying levels of authenticity/experimental evidence attached to each one.

\section{Discussion}

Unlike simple chromosomal translocations, large deletions associated with a certain condition can present many candidate genes for further study. In the context of psychiatric disorders velo-cardio-facial syndrome (VCFS or del22q11 syndrome) offers a model of how a cryptic deletion associated with schizophrenia has highlighted several candidate genes for future study [33-35].

We used two methods to screen for subtelomeric changes in our cohort of patients. The MAPH technique has proved a fast and accurate method for determining copy number changes in the human genome and represents a cost-effective route to the screening of large numbers of patients. In addition, the disorders that can be studied by this approach are limited only by the design of suitable primers so that screening for both single and contiguous gene disorders is feasible. MAPH has also been proved to be a simple method to map deletion breakpoints with greater resolution than FISH. The subtelomeric FISH approach is a more demanding approach because of the patient sample preparation, the requirement for specialised microscopy equipment, the cost of the commercial probe sets and the labour involved. Nevertheless, FISH has some advantages: the FISH approach is the only way to detect balanced chromosome rearrangements such as inversions and translocations. Other studies of subtelomeric regions in mental retardation subjects have identified such chromosomal aberrations. In addition, FISH has been a vital technique for identifying disrupted genes such as DISC1 in psychiatric patients with (non-subtelomeric) chromosomal rearrangements. Therefore, the selection of the screening technique should be determined by the number of cases to be studied and the nature of the abnormalities expected.

We have identified a subtelomeric deletion within our cohort of 69 patients using the MAPH and FISH methodologies. This $4 \mathrm{q}$ deletion is associated with a co-morbid phenotype of schizoaffective disorder and mild mental retardation (fullscale IQ between 60 and 70). Consent was not forthcoming to determine whether the deletion was of parental or de novo origin. However, psychiatric illness has not been diagnosed in other members of the family. We cannot, therefore, formally link the presence of the deletion with mental retardation and/or psychiatric illness in the patient. The annotation of transcripts at 4 q35.2 is currently an active area of research (see fig. 1 and table 2) because of good linkage evidence (LOD score of 3.2 for microsatellite marker D4S1652) from an extended Australian kindred multiply affected with bipolar affective disorder [36-38]. Importantly, the principal linkage region almost exactly matches the deletion interval observed in our patient. The $4 \mathrm{q}$ deletion patient has been diagnosed with schizoaffective disorder (DSM-IV 295.7) with periods of psychotic depression but also mood incongruent hallucinations and delusions. This is in contrast to the clear bipolar affective disorder diagnosed for members of the described linkage family. However, it has been repeatedly observed that schizoaffective disorders and bipolar affective disorders overlap clinically and are indeed often difficult to separate. One postulated explanation for the now frequently reported linkage overlaps between bipolar illness, schizoaffective disorders and schizophrenia is that the inherited susceptibility is for psychosis rather than a specific disorder (reviewed in [39]).

The subtelomeric region of $4 \mathrm{q}$ is also interesting because it contains a candidate gene, FRG1, for facioscapulohumeral muscular dystrophy. The $4 \mathrm{q}$ patient does not show any of the typical features of this disorder but this can be explained by the fact that copy number does not appear to be critical for the onset of the disorder [40]. Rather, the proximity of the gene to a variable number telomeric repeat sequence (D4Z4) seems to be the chief determinant of pathology [41].

Of the 69 patients with clear co-morbidity, one (1.4\%) possessed a single copy subtelomeric deletion. This frequency is in line with those from studies of individuals with mental retardation alone [18]. As more studies examine chromosomal integrity in people with mental retardation or other conditions we hope that replication of subtelomeric abnormalities will be observed, perhaps leading to the eventual clinical definition of range of 'subtelomeric syndromes' such as that recently described for the subtelomeric deletion of 1q [42].

\section{Conclusions}

The identification of the precisely delimited $4 \mathrm{q}$ deletion may contribute to the mapping of the susceptibility gene for psychiatric illness at this locus. The finding of bipolar affective disorder linkage to this region suggests that, in this case at least, the schizoaffective and mental retardation components to the co-morbid phenotype may be discrete and genetically separable in the manner of other contiguous gene disorders. If it is assumed that either component of the clinical phenotype is caused by haploinsufficiency then examining the comparative expression levels of candidate genes in normal, bipolarlinked and $4 \mathrm{q}$ deleted lymphoblastoid cell lines might provide a quick route to the identification of causative genes. Alternatively, gene association studies may be required to identify the candidate psychiatric illness gene at $4 \mathrm{q} 35$. The high rate of recombination in subtelomeric DNA means that a higher density of genetic markers will be required to establish linkage or association reliably; 
conversely, once detected, the high rate of recombination will allow high resolution fine mapping of significant loci.

\section{Competing interests \\ None declared.}

\section{Authors' contributions}

BSP participated in the design of the study and the FISH analysis and drafted the manuscript. EJH and JALA carried out all MAPH assays and associated statistical analyses. MPM carried out blood culture and FISH analysis. WJM conceived the study and was responsible for the generation of all clinical data, and DHRB and DJP participated in the study design and coordination. All authors read and approved the final manuscript.

\section{Acknowledgements}

The authors wish to thank Judy Fantes, Michael Ellis and Paul Perry for advice on fluorescence microscopy, and Jane Hewitt and Dan Bolland for advice on the $4 q$ physical map. The subtelomeric FISH work was supported by a small project grant from SHERT (RG45/0I) and the MAPH work by the Wellcome Trust, grant number 060578. MPM was supported by a grant from the Scottish Executive, Chief Scientist's Office and Wellcome Trust Genes to Cognition programme.

\section{References}

I. Knight SJ, Flint J: Perfect endings: a review of subtelomeric probes and their use in clinical diagnosis. J Med Genet 2000, 37(6):40I-409.

2. Kong A, Gudbjartsson DF, Sainz J, Jonsdottir GM, Gudjonsson SA, Richardsson B, Sigurdardottir S, Barnard J, Hallbeck B, Masson G, Shlien A, Palsson ST, Frigge ML, Thorgeirsson TE, Gulcher JR, Stefansson $\mathrm{K}$ : A high-resolution recombination map of the human genome. Nat Genet 2002, 3 I (3):24 I-247.

3. van Karnebeek CD, Koevoets C, Sluijter S, Bijlsma EK, Smeets DF, Redeker EJ, Hennekam RC, Hoovers JM: Prospective screening for subtelomeric rearrangements in children with mental retardation of unknown aetiology: the Amsterdam experience. J Med Genet 2002, 39(8):546-553.

4. Knight SJ, Regan R, Nicod A, Horsley SW, Kearney L, Homfray T, Winter RM, Bolton P, Flint J: Subtle chromosomal rearrangements in children with unexplained mental retardation. Lancet 1999, 354:|676-|68|.

5. Sismani C, Armour JA, Flint J, Girgalli C, Regan R, Patsalis PC: Screening for subtelomeric chromosome abnormalities in children with idiopathic mental retardation using multiprobe telomeric FISH and the new MAPH telomeric assay. Eur J Hum Genet 200I, 9(7):527-532.

6. Baker E, Hinton L, Callen DF, Altree M, Dobbie A, Eyre HJ, Sutherland GR, Thompson E, Thompson P, Woollatt E, Haan E: Study of $\mathbf{2 5 0}$ children with idiopathic mental retardation reveals nine cryptic and diverse subtelomeric chromosome anomalies. Am J Med Genet 2002, 107(4):285-293.

7. Joyce CA, Dennis NR, Cooper S, Browne CE: Subtelomeric rearrangements: results from a study of selected and unselected probands with idiopathic mental retardation and control individuals by using high-resolution G-banding and FISH. Hum Genet 200I, 109(4):440-45I.

8. Lamb A, Lytle C, Aylsworth A, Powell C, Rao K, Hendrickson M, Carey J, Opitz J, Viskochil D, Leonard C, Brothman A, Stephan M, Bartley J, Hackbarth M, McCarthy D, Proffit J: Low proportion of subtelomeric rearrangements in a population of patients with mental retardation dysmorphic features. Am J Hum Genet Suppl 1995, 59:A169.

9. Vorsanova SG, Yurov YB, Kolotii AD, Demidova IA, Novikova IM: I6q subtelomeric deletion in proband with congenital malformations and mental retardation. Tsitol Genet 2000, 34(6):72-74.
10. Fan YS, Zhang Y, Speevak M, Farrell S, Jung JH, Siu VM: Detection of submicroscopic aberrations in patients with unexplained mental retardation by fluorescence in situ hybridization using multiple subtelomeric probes. Genet Med 200I, 3(6):4|6-42|

II. Riegel M, Baumer A, Jamar M, Delbecque K, Herens C, Verloes A, Schinzel A: Submicroscopic terminal deletions and duplications in retarded patients with unclassified malformation syndromes. Hum Genet 200I, 109(3):286-294.

12. Clarkson B, Pavenski K, Dupuis L, Kennedy S, Meyn S, Nezarati MM, Nie G, Weksberg R, Withers S, Quercia N, Teebi AS, Teshima I: Detecting rearrangements in children using subtelomeric FISH and SKY. Am J Med Genet 2002, I07(4):267-274.

13. Jalal SM, Harwood AR, Sekhon GS, Pham Lorentz C, Ketterling RP, Babovic-Vuksanovic D, Meyer RG, Ensenauer R, Anderson MH Jr, Michels VV: Utility of subtelomeric fluorescent DNA probes for detection of chromosome anomalies in 425 patients. Genet Med 2003, 5(I):28-34.

14. Helias-Rodzewicz Z, Bocian E, Stankiewicz P, Obersztyn E, Kostyk E, Jakubow-Durska K, Kutkowska-Kazmierczak A, Mazurczak T: Subtelomeric rearrangements detected by FISH in three of 33 families with idiopathic mental retardation and minor physical anomalies. J Med Genet 2002, 39(9):53.

15. Anderlid BM, Schoumans J, Anneren G, Sahlen S, Kyllerman M, Vujic M, Hagberg B, Blennow E, Nordenskjold M: Subtelomeric rearrangements detected in patients with idiopathic mental retardation. Am J Med Genet 2002, 107(4):275-284.

16. Rio M, Molinari F, Heuertz S, Ozilou C, Gosset P, Raoul O, CormierDaire V, Amiel J, Lyonnet S, Le Merrer M, Turleau C, de Blois MC, Prieur M, Romana S, Vekemans M, Munnich A, Colleaux L: Automated fluorescent genotyping detects $10 \%$ of cryptic subtelomeric rearrangements in idiopathic syndromic mental retardation. J Med Genet 2002, 39(4):266-270.

17. Viot G, Gosset P, Fert S, Prieur M, Turleau C, Raoul O, De Blois MC Lyonnet S, Munnich A, Vekemans M: Cryptic subtelomeric rearrangements detected by FISH in mentally retarded and dysmorphic patients. Am J Hum Genet Suppl I998, 63:AI0.

18. De Vries BB, Winter R, Schinzel A, van Ravenswaaij-Arts C: Telomeres: a diagnosis at the end of the chromosomes. J Med Genet 2003, 40(6):385-398.

19. Flint J, Wilkie AO, Buckle VJ, Winter RM, Holland AJ, McDermid HE: The detection of subtelomeric chromosomal rearrangements in idiopathic mental retardation. Nat Genet 1995, 9(2): $132-140$.

20. Knight SJ, Horsley SW, Regan R, Lawrie NM, Maher EJ, Cardy DL, Flint J, Kearney L: Development and clinical application of an innovative fluorescence in situ hybridization technique which detects submicroscopic rearrangements involving telomeres. Eur J Hum Genet 1997, 5(I): I-8.

21. Armour JA, Sismani C, Patsalis PC, Cross G: Measurement of locus copy number by hybridisation with amplifiable probes. Nucleic Acids Res 2000, 28(2):605-609.

22. Hollox EJ, Atia T, Cross G, Parkin T, Armour JA: High throughput screening of human subtelomeric DNA for copy number changes using multiplex amplifiable probe hybridisation (MAPH). I Med Genet 2002, 39(I I):790-795.

23. Hollox EJ, Akrami SM, Armour JA: DNA copy number analysis by MAPH: molecular diagnostic applications. Expert Rev Mol Diagn 2002, 2(4):370-378.

24. Kriek M, White SJ, Bouma MC, Dauwerse HG, Hansson KB, Nijhuis $J V$, Bakker B, van Ommen G], den Dunnen JT, Breuning MH: Genomic imbalances in mental retardation. J Med Genet 2004, 41:249-255.

25. Berrettini $\mathrm{WH}$ : Are schizophrenic and bipolar disorders related? A review of family and molecular studies. Biol Psychiatry 2000, 48(6):531-538.

26. Millar JK, Wilson-Annan JC, Anderson S, Christie S, Taylor MS, Semple CA, Devon RS, StClair DM, Muir WJ, Blackwood DH, Porteous DJ: Disruption of two novel genes by a translocation co-segregating with schizophrenia. Hum Mol Genet 2000 9(9):1415-1423.

27. Baysal BE, Willett-Brozick JE, Badner JA, Corona W, Ferrell RE, Nimgaonkar VL, Detera-Wadleigh SD: A mannosyltransferase gene at I Iq23 is disrupted by a translocation breakpoint that cosegregates with bipolar affective disorder in a small family. Neurogenetics 2002, 4(I):43-53. 
28. Gecz J, Barnett S, Liu J, Hollway G, Donnelly A, Eyre H, Eshkevari HS, Baltazar R, Grunn A, Nagaraja R, Gilliam C, Peltonen L, Sutherland GR, Baron M, Mulley JC: Characterization of the human glutamate receptor subunit 3 gene (GRIA3), a candidate for bipolar disorder and nonspecific $X$-linked mental retardation. Genomics 1999, 62(3):356-368.

29. Doody GA, Johnstone EC, Sanderson TL, Owens DG, Muir WJ: 'Pfropfschizophrenie' revisited. Schizophrenia in people with mild learning disability. Br J Psychiatry 1998, I 73:| 45-I53.

30. Sanderson TL, Best J, Doody GA, Owens DG, Johnstone EC: Neuroanatomy of comorbid schizophrenia and learning disability: a controlled study. Lancet 1999, 354:|867-|87|

31. Endicott J, Spitzer RL: A diagnostic interview: the schedule for affective disorders and schizophrenia. Arch Gen Psychiatry 1978 , 35:837-844

32. American Psychiatric Association: Diagnostic and Statistical Manual of Mental Disorders. Text Revision 4th edition. American Psychiatric Association, Washington, DC; 2000.

33. McDermid HE, Morrow BE: Genomic disorders on 22q I I. Am J Hum Genet 2002, 70:1077-1088.

34. Murphy KC, Owen MJ: Velo-cardio-facial syndrome: a model for understanding the genetics and pathogenesis of schizophrenia. Br J Psychiatry 200I, I 79:397-402.

35. Lindsay EA: Chromosomal microdeletions: dissecting del22q I I syndrome. Nat Rev Genet 200I, 2:858-868.

36. Adams LJ, Mitchell PB, Fielder SL, Rosso A, Donald JA, Schofield PR: A susceptibility locus for bipolar affective disorder on chromosome 4q35. Am J Hum Genet 1998, 62(5): I 084- I091.

37. Blair IP, Adams LJ, Badenhop RF, Moses MJ, Scimone A, Morris JA, Ma L, Austin CP, Donald JA, Mitchell PB, Schofield PR: A transcript map encompassing a susceptibility locus for bipolar affective disorder on chromosome 4q35. Mol Psychiatry 2002, 7(8):867-873.

38. Badenhop RF, Moses MJ, Scimone A, Adams LJ, Kwok JB, Jones AM, Davison G, Evans MR, Kirkby KC, Hewitt JE, Donald JA, Mitchell PB, Schofield PR: Genetic refinement and physical mapping of a 2.3 Mb probable disease region associated with a bipolar affective disorder susceptibility locus on chromosome 4q35. Am J Med Genet 2003, I I 7B(I):23-32.

39. Bramon E, Sham PC: The common genetic liability between schizophrenia and bipolar disorder: a review. Curr Psychiatry Rep 200I, 3(4):332-337.

40. Tupler R, Berardinelli A, Barbierato L, Frants R, Hewitt JE, Lanzi G, Maraschio P, Tiepolo L: Monosomy of distal 4q does not cause facioscapulohumeral muscular dystrophy. J Med Genet 1996 33(5):366-370.

4I. Lemmers RJ, de Kievit P, Sandkuijl L, Padberg GW, van Ommen GJ, Frants RR, van der Maarel SM: Facioscapulohumeral muscular dystrophy is uniquely associated with one of the two variants of the 4q subtelomere. Nat Genet 2002, 32(2):235-236.

42. De Vries BB, Knight SJ, Homfray T, Smithson SF, Flint J, Winter RM: Submicroscopic subtelomeric I qter deletions: a recognisable phenotype? J Med Genet 200I, 38(3): I75-I78.

\section{Pre-publication history}

The pre-publication history for this paper can be accessed here:

http://www.biomedcentral.com/1471-2350/5/21/prepub

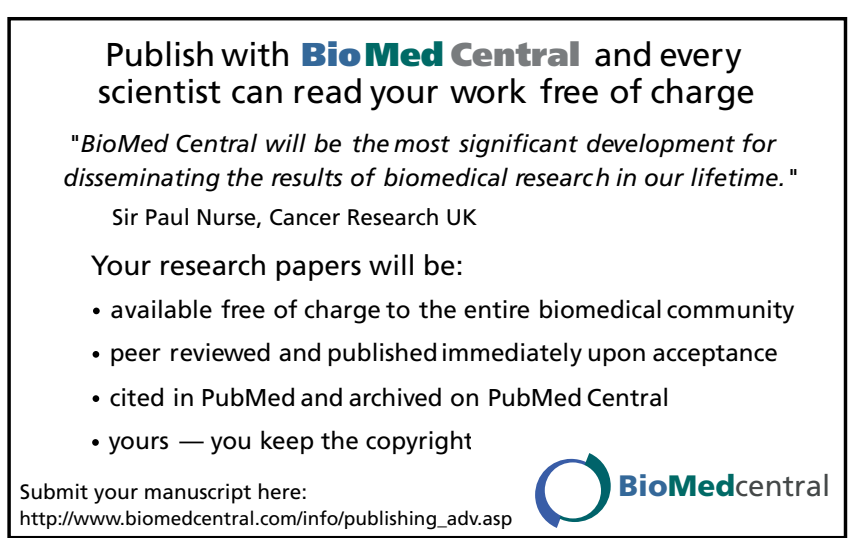

